\title{
The College's Clinical Guideline Development Programme
}

\author{
Chris Thompson
}

In 1993 the College successfully applied for central audit funds from the Department of Health to set up a programme to develop clinical guidelines for psychiatry. This was to be run by the College Research Unit, the deputy director of which (Dr Paul Lelliott, now the director) has been responsible for the bid. It was very clear at the time of the bid that clinical guidelines were going to be developed with or without the involvement of the profession. Indeed the College has already been in correspondence with the Department of Health about a guideline for the assessment of deliberate self harm which they have endorsed, but which was produced without the adequate involvement of psychiatrists. The Effective Health Care Bulletins are another example of guidance which does not always carry the profession's confidence.

However, the College did not go into this process reluctantly by any means. Our positive attitude is entirely in keeping with our history of setting and raising standards in the speciality. Previously our main tool has been the approvals exercise for training schemes and the parallel exercise of the JCHPT for higher training. But there is only so much that a visiting organisation can achieve in setting standards of service. This new College activity. together with the development of local audit programmes, offers a new tool for individual clinicians to assess their own and, by consent, their colleagues' practice against systematically developed guidelines.

The article by Sarah Marriott, (pages 403406) explains the methods which we as a College will use to ensure that our guidelines have the confidence of the profession (and others in related professions) and that they will therefore be effective and helpful to clinicians and clinical managers. In brief, there are several stages, each of which requires extensive consultation.

The first stage is to construct a priority list of topics for which guidelines are most urgent.
This has now been done and the highest priority of all the groups polled is the immediate management of the severely mentally ill who pose a risk to themselves or others. Once the priority has been set comes the need to identify the scope of the guideline, i.e. what should it include and exclude. A working group is now being established to develop this guideline. The first thing they will have to do is to look for the scientific evidence because all guidelines should be explicit about which recommendations are based on experimental evidence and which on clinical opinion and consensus.

Writing a good guideline takes time. We anticipate that the process will take 18 months to two years for each. We expect to be able to handle about two new guidelines per year, so eventually they will be appearing with about that frequency, but there will be a delay of a year or so before members will have the first one available.

There has been some concern that guidelines will be used in litigation for negligence. In the sense that they formulate accepted practice it is true that they may make it easier for lawyers and others to understand the norms of medical care. However the test of negligence will not change. If there remains a reputable body of opinion that disagrees with all or part of a guideline then there will be a defence for any doctor who is not practising in accordance with it. However, if the guideline has been well constructed such disagreements should only arise for two reasons. First new knowledge may have arrived since the guideline was written, 1.e. it is out of date scientifically and needs replacing. Second, a lack of scientific evidence has left room for clinical consensus which is not complete.

The American Psychiatric Association has been publishing guidelines since 1991 and they have a standard 'disclaimer' which appears in every guideline. This includes the following sentence: 
"The ultimate judgement regarding a particular clinical procedure or treatment plan must be made by the psychiatrist in light of the clinical data presented by the patient and the diagnostic and treatment options available".

We would not disagree with that. Guidelines are first and foremost educational tools which should be designed to support clinicians in their decisions. They are sometimes misconstrued as being imposed from outside or above. It is important to dispel this impression and we have started to do this by having the College engaged in the process since only the College has the necessary consultation networks to generate a sense of ownership among psychiatrists. Even so those of us working on guidelines at the 'centre' are well aware that to be really useful each guideline will need to be modified locally to make it more relevant and specific to the hospital or community in which it is to be applied.

Nevertheless, guidelines will not always live up to their ideal. The process will have to be iterative, i.e. any one guideline will have to have a limited lifespan and will have to be rewritten at regular intervals taking account of changes in knowledge, practice and unanticipated problems with previous drafts. Medicine does not stand still and this iterative approach to guidelines acknowledges that.

Finally I am delighted to have been involved with the birth of this new activity for the College. It has demonstrated the enormous advantage to the College of having a research unit. All credit must go to Dr Lelliott and Dr Marriott for bringing the difficult early stages of the process to a successful conclusion. We now also have Claire Palmer as the College staff member with responsibility for facilitating clinical guidelines. She brings immense experience from her previous role in district audit activities. We therefore have a very strong team. If College members or fellows wish to know more about these activities the library keeps a database of audit and guideline literature and Claire Palmer is available for enquiries about the progress of the College's programme. We wish to involve College members in all stages of the process from priority setting to final approval, which will remain the responsibility of your representatives on Council.

Chris Thompson, Registrar, Royal College of Psychiatrists 